\title{
Identification of amino acid variation in the prion protein associated with classical scrapie in Canadian dairy goats
}

\author{
Vythegi Srithayakumar ${ }^{1,3^{*}}$, Gordon B. Mitchell ${ }^{2}$ and Bradley N. White ${ }^{1}$
}

\begin{abstract}
Background: A clear association of amino acid variation in the prion protein gene (PRNP) with susceptibility and resistance to classical scrapie exists in sheep, but not in goats. In this study we examined DNA sequence variation in the PRNP of 149 animals from two scrapie-infected herds of Saanen dairy goats, and identified 6 nonsynonymous variants in the coding region.

Results: In the larger herd, all of the 54 scrapie-affected goats tested had at least one allele with the arginine (R) codon at position 211, with 52 being homozygous for that variant. No animal homozygous for the glutamine (Q) codon at 211 were affected and only two heterozygotes (R/Q) were affected. A weak association was found at position 146 and no significant associations were found with amino acid variation at the remaining four variant positions (142, 143, 222 and 240), however, the allelic variation was low. Similar patterns were observed in the second scrapie-affected herd.

Conclusion: We also evaluated previous studies on goat herds affected with scrapie and this relationship of $\mathrm{R}$ susceptibility and Q resistance at 211 was present independent of the genotypes at the other positions including 222. The fact that glutamine at 211 provides a significant protective property to scrapie irrespective of the other positions could be important for breeding strategies aimed at improving herd resistance to scrapie, while maintaining important productivity traits.
\end{abstract}

Keywords: Scrapie, Goat, Prion, Resistance, Susceptibility, Breeding, Variation

\section{Background}

Scrapie is a fatal neurodegenerative disease that affects sheep and goats. It is classified as a transmissible spongiform encephalopathy (TSE) belonging to a group of prion diseases, which includes Creutzfeldt-Jakob disease in humans, bovine spongiform encephalopathy (BSE) in cattle, and chronic wasting disease in cervids. Prion diseases not only have a serious impact on health and welfare, but control of these diseases impacts animal movement and trade. Prion diseases can occur sporadically as well as through heredity or infectious transmission routes [1] but pathogenesis is contingent on conversion of the normal

\footnotetext{
* Correspondence: vythegisrithayakumar@trentu.ca

${ }^{1}$ Natural Resources DNA Profiling and Forensics Centre, DNA Building, Trent University, 2140 East Bank Drive, Peterborough, ON, Canada

${ }^{3}$ Livestock Gentec, Department of Agricultural, Food and Nutritional Science, University of Alberta, Edmonton, AB T6G2P5, Canada

Full list of author information is available at the end of the article
}

host prion protein $\left(\operatorname{PrP}^{\mathrm{C}}\right)$ to a disease-associated form $\left(\operatorname{PrP}^{\mathrm{SC}}\right)$. In sheep and goats, scrapie is characterized by the deposition of this abnormal, protease resistant prion protein $\left(\mathrm{PrP}^{\mathrm{Sc}}\right)$ in the central nervous system and peripheral tissues $[2,3]$. The host prion gene (PRNP) encodes the prion protein $\left(\operatorname{PrP}^{C}\right)$ and mutations within this gene have been associated with differential resistance and susceptibility to scrapie (as reviewed [4]).

Genetic resistance to scrapie is well established in sheep and three-codon PRNP genotypes have typically been utilized for risk assessment (as reviewed in [4]). The association of these three amino acid codons at positions 136, 154 and 171 produces 5 haplotypes (ARQ, VRQ, AHQ, ARR, ARH) and 15 genotypes [4, 5]. The ARR haplotype is associated with high resistance, whereas VRQ or ARQ are associated with higher susceptibility to scrapie [6, 7]. Sheep breeding programs selecting for the ARR genotype have been widely used for scrapie 
control and eradication programs in Europe and North America [8]. Patterns of associations to scrapie resistance and susceptibility based on the three codons used for sheep do not hold true in goats.

Although the natural occurrence of scrapie in goats appears generally lower than that in sheep, active surveillance reports suggest that the prevalence rates in goats may be underestimated in some countries [9]. There have been a number of studies that examined resistance and susceptibility to scrapie in goats from European countries (e.g., France, Italy, United Kingdom, Greece), where the goat populations are large and the incidence of scrapie has been high. These studies have characterized PRNP sequence variation in goats, and have reported a number of polymorphisms in goat populations worldwide [10-25]. In particular, thirty nine amino acid substitutions have been described, of which only six G127S [18], I142M [26], N146S/D [12], H154R [10, 12, 14, 19], R211Q [19], and Q222K [11, 14, 19] have been associated with resistance or susceptibility to scrapie in goats. At least 16 synonymous silent mutations have also been documented. To date, 39 out of the 256 codons have been shown to be polymorphic across goat breeds and generally 6 to 12 are described as polymorphic within a given goat breed. While some of the polymorphic sites are similar in sheep and goats, species-specific variation, like that observed for $A_{136} R_{154} R_{171}$, are also present (as reviewed in [4]).

Despite the high amount of variation observed in the $P R N P$ in various goat breeds, clear associations with scrapie susceptibility or resistance are limited. In the studies that have suggested associations with PRNP polymorphisms, the power of the analyses is often weak because of the relatively low frequencies of the putative resistant allele and the emphasis on identifying resistance alleles rather than susceptibility alleles. The unaffected animals represent a mixture of resistant and susceptible animals of varying exposure status, while the affected animals are more homogeneous in susceptibility traits. The absence of clearly identified variation, which is associated with scrapie in goats, has limited the implementation of breeding strategies to eliminate scrapie sensitive alleles in goat herds.

The objectives of this study were: (i) to identify the variation in PRNP genotypes in 2 herds of Saanen dairy goats with scrapie affected animals; (ii) to examine associations between $\operatorname{PrP}^{\mathrm{C}}$ amino acid variation and scrapie disease in the largest herd and (iii) to validate the associations using the second scrapie affected herd together with published associations.

\section{Methods}

\section{Scrapie affected herds}

The first scrapie affected dairy goat herd was composed of 331 Saanen goats greater than 12 months of age. The herd was depopulated as part of routine disease control measures following the detection and confirmation of a scrapie-positive goat. Jugular blood was sampled in EDTA-vacutainer tubes for DNA extraction and the obex and retropharyngeal lymph nodes were removed for scrapie diagnostic testing. Initial testing of obex and lymph node tissues was conducted using a commercially available ELISA (Bio-Rad TeSeE ${ }^{\circ}$ ELISA, Bio-Rad Laboratories, Hercules, CA). Confirmatory testing was subsequently performed using immunohistochemistry with antibodies F89 and F99, and western immunoblot (Bio-Rad TeSeE ${ }^{\circ}$ western immunoblotting kit, Bio-Rad Laboratories) as previously described [27]. An animal was considered positive for scrapie if it was positive in at least one tissue by the confirmatory tests. A total of 66 animals were found positive for classical scrapie. PRNP was sequenced for 54 of the 66 scrapie-affected and 56 of the unaffected animals.

A second, smaller scrapie-affected herd that comprised 130 Saanen goats greater than 12 months of age was also identified and subjected to depopulation. Following the testing regime described above, 13 animals were identified as classical scrapie positive. PRNP was sequenced for 10 scrapie-affected and 29 unaffected animals.

\section{PRNP sequencing and genotyping}

Genomic DNA was extracted from EDTA-preserved whole blood using the MagNa Pure DNA Isolation Kit for blood (Roche Applied Sciences) as per manufacturer's instructions, and was quantified using PicoGreen. The Goat PRNP reference sequence was obtained from Genbank (accession \# X74758) and primers were designed to amplify the ORF of PRNP (PRNP2-F: AGCTGATGCCAGTGCTATGC and PRNP4R: GTGGCCTCCTTCCAGACTTG).

PCR buffer components were in the following concentrations: $1 \times$ PCR buffer (Invitrogen), $0.2 \mathrm{mM}$ of each dNTP, $1.5 \mathrm{mM} \mathrm{MgCl} 2,0.3 \mu \mathrm{M}$ of forward primer, $0.3 \mu \mathrm{M}$ of reverse primer, $0.05 \mathrm{U} / \mu \mathrm{L}$ of Taq DNA polymerase (Invitrogen), $10 \mathrm{ng}$ of DNA and $\mathrm{ddH} 2 \mathrm{O}$ for a total volume of $20 \mu \mathrm{l}$. PCR conditions used for amplification were as follows: initial denaturation at $94{ }^{\circ} \mathrm{C}$ for $5 \mathrm{~min}$; [denaturation at $94{ }^{\circ} \mathrm{C}$ for $30 \mathrm{~s}$, annealing at $60{ }^{\circ} \mathrm{C}$ for $1 \mathrm{~min}$, extension at $72{ }^{\circ} \mathrm{C}$ for $1 \min 30 \mathrm{~s}$ ] $\times$ 35 cycles; final extension at $72{ }^{\circ} \mathrm{C}$ for $15 \mathrm{~min}$; and $4^{\circ}$ $\mathrm{C}$ hold. Two $\mu \mathrm{l}$ of the amplified product were subjected to agarose gel electrophoresis to confirm amplification. PCR products were purified using ExoSAP (New England BioLabs) following the manufacturer's instructions. BigDye ${ }^{\bullet}$ Terminator v3.1 Cycle Sequencing Kit (Applied Biosystems) was used to sequence the fragments, using both the forward and reverse primers. Sequences were edited and aligned to Ovine and Caprine PRNP using MEGA ${ }^{\text {tw }} 6.0$ [28]. 
Analysis of genotypes in affected and unaffected samples Comparison of the genotype frequencies of affected and unaffected groups were carried out using logistic regression models fitted to scrapie status of goats in the affected groups. When there were no positive scrapie cases, Fisher's exact test was used.

\section{Relative susceptibility of genotypes to scrapie}

Herd 1 consisted of 331 animals more than 12 months of age and 66 tested scrapie positive; the remaining 265 animals, consisted of animals that tested scrapie negative on ELISA. The scrapie negative animals may have been exposed to the disease and not succumbed or simply may not have been exposed to the disease. In order to estimate the relative susceptibility of different genotypes to scrapie, the frequencies of alleles and genotypes in the pre-exposed herd one were estimated. We assumed the genotypes of the 56 unaffected samples that were genotyped were representative of the 209 unaffected animals that were not genotyped and the genotypes of the 54 affected animals were representative of the12 affected animals that were not genotyped. The percentages of each genotype in the pre-exposed herd that became scrapie positive were compared.

\section{Results \\ PRNP variation and allele frequencies in 2 scrapie affected Ontario Saanen herds}

The open reading frames of the PRNP [5] were sequenced in 54/66 of the affected animals and 56/265 of the unaffected animals. A total of eight variable sites were found, with six non-synonymous substitutions (codon positions: 142, 143, 146, 211, 222 and 240) and two synonymous substitutions (Fig. 1). Amino acids are designated by the single letter codes that give six letter alleles or haplotypes. Initially allele haplotypes were assigned based on homozygous animals; heterozygous animals were genotyped based on the confirmed alleles in the homozygotes. This left haplotype uncertainty in three of the ten alleles that were in low frequency, (Table 1) and the genotypes with those alleles (Table 2). The haplotype frequencies for each of the two herds show a high prevalence of four alleles (Table 1).

\section{Association of variants with scrapie susceptibility}

We compared the genotypes of affected and unaffected animals in order to assess the association with scrapie susceptibility using logistic regression (Table 2). The genotypes IHNRQP/IHNRQP and IHNRQS/IHNRQP, were seen in significantly higher frequency in scrapie positive animals than scrapie negative animals. Conversely, IHNQQS/IHNRQP and IHNQQS/IHNRQS were present predominantly in scrapie negative animals. Next, we examined the relative susceptibility of the different genotypes to scrapie.

We focused on the affected animals, as the unaffected sample represents a mixture of potentially resistant animals as well as unexposed or less exposed animals (Table 2). The homozygous genotype IHNRQP/IHNRQP was estimated to be present in 53 individuals in the preexposed herd and 16 were found in the scrapie positive sample, while the heterozygote IHNQQS/IHNRQP was estimated to be present in 67 individuals prior to exposure and only one was found in the scrapie positive samples. In order to identify the amino acids conferring scrapie susceptibility we analysed the six variable positions individually.

The genotype frequencies of the affected animals were compared to the expected frequencies based on the preexposed herd and the null hypothesis that the affected animals represent a random sample of genotypes in the herd (Table 3). A significant difference was found at position 211, and a weaker significance at 146. Arginine (R) at 211 was clearly associated with susceptibility while glutamine (Q) was associated with resistance in the $\mathrm{RQ}_{211}$ heterozygote. There were fewer affected animals in herd 2 but all were $R R_{211}$, consistent with $R$ being a susceptibility allele (Table 3 ).

When we examined the genotype estimates of the preexposed herd at position 211, the relative risk of developing the disease for the genotype $R_{211}$ and $R_{211}$ was clear, with 64 of $182 R_{211}$ being affected while only two of $125 \mathrm{RQ}_{211}$ were affected. These data highlight the protective effect of $\mathrm{Q}$ in the heterozygote making it approximately $22 \times$ more resistant than RR (Table 4 ).

The results in Tables 3 and 4 show a clear association between $R_{211}$ and scrapie susceptibility. In the literature there are reported patterns of resistance for $\mathrm{M}_{142}, \mathrm{~S}_{146}$, $R_{211}$ and $K_{222}[11,14,19,21,29,30]$, but the power of the analyses for these codons are often weak because of low allele frequencies of the proposed resistant alleles (Table 5). We examined the 544 scrapie affected samples described in the literature, and this showed most are homozygous for the proposed susceptibility alleles at positions 142, 146, 211 and 222. This is because the resistant alleles are in very low frequency in most herds in Europe and the US [11, 13, 14, 19, 21, 29, 30] and emphasises the importance of establishing the allele frequencies in the herds when associating resistance and susceptibility with genotypes. As with the data presented here, the heterozygote $\mathrm{RQ}_{211}$ is found significantly less frequently than homozygous $\mathrm{RR}_{211}$, and the $\mathrm{QQ}_{211}$ genotype was not seen in any affected animal.

\section{Discussion}

Scrapie poses a threat to the Canadian goat industry as herds on farms that test positive are entirely eradicated, 


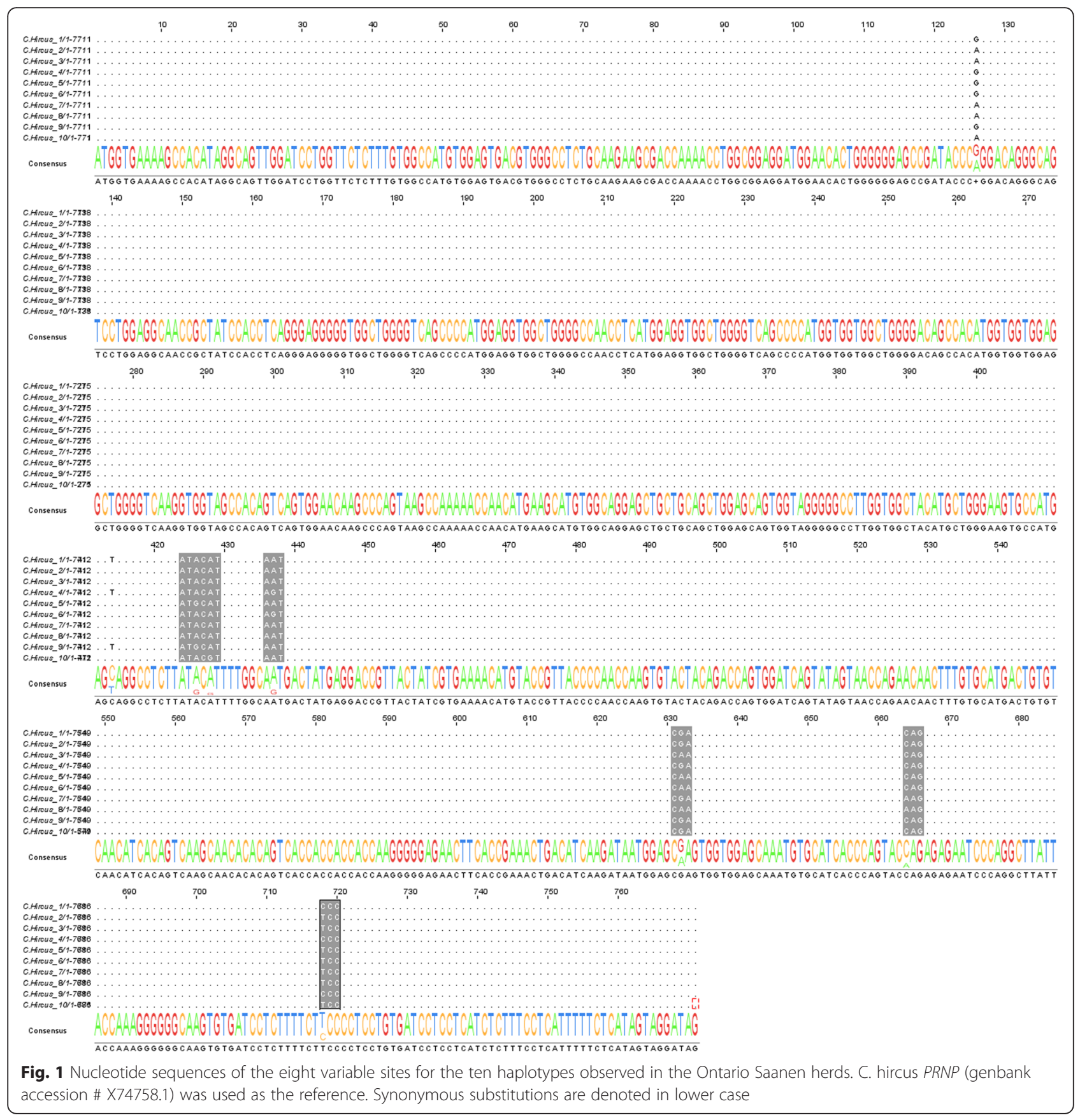

and its presence limits the international export of goat genetics. Control of scrapie in sheep and goats requires knowledge of the PRNP genotypes which influence disease susceptibility. In sheep there is a clear association of amino acid variation at three positions in PRNP to susceptibility and resistance to scrapie. There are weaker associations with four positions in goats and this seems to be caused by low frequencies of variants, which in turn impact the power of the analyses. Analyses have also focused on identifying resistant alleles in unaffected animals that represent a mixture of resistant and unexposed animals. In this study, we had samples from a large herd of Saanen dairy goats with 66 affected individuals and a smaller herd with 13 affected animals.

The previous studies on goat scrapie have identified a number of variants in the different breeds and herds, which are associated with a lower incidence of scrapie $[10-12,14,19,26]$. These include $\mathrm{M}_{142}, \mathrm{~S}_{146}, \mathrm{Q}_{211}$ and $\mathrm{K}_{222}$, which were present in the two herds we examined; but apart from $\mathrm{Q}_{211}$, the frequencies of the other variants were low. However, these variants were only found in the unaffected animals in both herds. 
Table 1 Allele frequencies for PRNP in herds 1 and 2

\begin{tabular}{lllllllll}
\hline \multicolumn{1}{l}{ Amino acid position } \\
\hline & 142 & 143 & 146 & 211 & 222 & 240 & Herd 1 & Herd 2 \\
1 & I & H & N & R & Q & P & 0.459 & 0.526 \\
2 & - & - & - & - & - & S & 0.305 & 0.231 \\
3 & - & - & - & Q & - & S & 0.159 & 0.090 \\
4 & - & - & S & - & - & - & 0.032 & 0.090 \\
$5^{*}$ & M & - & - & Q & - & S & 0.005 & 0.000 \\
$6^{*}$ & - & - & S & Q & - & S & 0.005 & 0.000 \\
$7^{*}$ & - & - & - & Q & K & S & 0.005 & 0.000 \\
8 & - & - & - & - & K & S & 0.014 & 0.000 \\
9 & M & - & - & - & - & - & 0.014 & 0.064 \\
10 & - & R & - & - & - & S & 0.005 & 0.000 \\
\hline
\end{tabular}

$¥$ unconfirmed haplotypes

\section{PRNP variation in Ontario Saanens}

Thirty-seven amino acid substitutions have been previously described in the open reading frame of PRNP in goats around the world. The six polymorphisms found in the Saanens from Ontario have been previously described $[11,13,14,19,26]$. It is usual to observe only a subset of the global goat PRNP polymorphisms in a given breed or herd. Previous studies have found polymorphic positions ranging from 5 to 14 [11, 13, 18-20]. Saanens often have six polymorphic codons, with the specific position differing among different herds in different countries. Three of the six (142, 211, and 240) were found in Italian Saanens; four (142, 211, 222 and 240) were found in the French and Spanish Saanens. The remaining two polymorphic codons 143 and 146 that were seen in low allele frequencies ( 0.34 and $5 \%$, respectively), have been reported in Saanens crossbred with Hellenic and Damascus breeds, respectively [10, 12, 24]. As the Saanen breed originated from Switzerland, these similarities and differences are the result of founder effects combined with cross breeding with local goat breeds.

Of the ten haplotypes found in this study, three (IHNRQP, IHNRQS and IHNQQS) were present in $90 \%$ of the sampled animals. The two major PRNP haplotypes (IHNRQP and IHNRQS) differed from one another by the presence of proline $(\mathrm{P})$ or serine $(\mathrm{S})$ at position 240. In both of the herds investigated, $\mathrm{P}_{240}$ was slightly higher in frequency $(55 \%)$ compared to $\mathrm{S}_{240}(45 \%)$. This pattern has been noted in French Saanens [19, 21], Italian [11, 14], Spanish [20], British [18]; North American [13] and Greek goats [10, 23, 29, 30]. When we estimated the haplotype and genotype frequencies for all the animals in both herds, comparable trends were observed for the two main haplotypes (IHNRQP and IHNRQS); however, for the other haplotypes present in low frequencies, significant differences were present between the two herds. Low haplotypic frequencies are usually encountered when examining PRNP variation in goat herds $[10,11$, $14,19-21,23]$.

Table 2 Comparison of genotypes among the complete herd, affected and unaffected animals in herd 1. Logistic regression was used to compare affected and unaffected animals

\begin{tabular}{|c|c|c|c|c|c|}
\hline PRNP genotype & Pre-exposure ${ }^{a}$ & $\begin{array}{l}\text { Scrapie positive } \\
\text { sample }\end{array}$ & $\begin{array}{l}\text { Scrapie negative } \\
\text { sample }\end{array}$ & OR $(95 \%$ Cl) & $P$-value \\
\hline IHNRQP/IHNRQP & 53 & 16 & 7 & 2.947(1.089-7.973) & 0.033 \\
\hline IHNRQS/IHNRQP & 63 & 28 & 6 & 8.974(3.261-24.699) & $<0.005$ \\
\hline IHNRQS/IHNRQS & 13 & 7 & 1 & $8.191(0.949-70.704)$ & 0.055 \\
\hline MHNRQP/IHNRQS & 14 & 0 & 3 & $N D^{\ddagger}$ & - \\
\hline MHNQQS/IHNRQP & 5 & 0 & 1 & ND & - \\
\hline IHNRQP/IRNRQS & 1 & 1 & 0 & ND & - \\
\hline IHSRQP/IHNRQP & 9 & 0 & 2 & ND & - \\
\hline IHSRQP/IHNRQS & 14 & 0 & 3 & ND & - \\
\hline IHSRQP/IHSRQP & 5 & 0 & 1 & ND & - \\
\hline ihsqqs/IHNRQP & 5 & 0 & 1 & ND & - \\
\hline IHNQQS/IHNRQP & 67 & 1 & 14 & $0.057(0.007-0.459)$ & 0.007 \\
\hline IHNQQS/IHNRQS & 44 & 1 & 9 & $0.098(0.012-0.827)$ & 0.033 \\
\hline IHNQQS/IHNQQS & 24 & 0 & 5 & ND & - \\
\hline IHNRKS/IHNRQP & 5 & 0 & 1 & ND & - \\
\hline IHNRKS/IHNRQS & 5 & 0 & 1 & ND & - \\
\hline IHNRKS/IHNQQS & 5 & 0 & 1 & ND & - \\
\hline Total & 331 & 54 & 56 & - & - \\
\hline
\end{tabular}

${ }^{a}$ number of genotypes pre-exposure was estimated as described in the methods

${ }^{\ddagger}$ OR could not be determined (ND) for genotypes without any scrapie positive cases 
Table 3 Comparison of observed and expected numbers of scrapie positive samples for each amino acid variant. Allele frequencies of the pre-exposed herd are indicated in parentheses. $P$-values of $<0.05$ are indicated in bold. Chi-square analysis was used for herd 1, and Fisher's exact test was used for herd 2 as the sample size was low

\begin{tabular}{|c|c|c|c|c|c|}
\hline \multirow[b]{3}{*}{ Codon } & \multirow[b]{3}{*}{ Genotype } & \multicolumn{4}{|c|}{ Numbers in Scrapie positive samples } \\
\hline & & \multicolumn{2}{|l|}{ Herd \#1 } & \multicolumn{2}{|l|}{ Herd \#2 } \\
\hline & & Observed & Expected $^{\neq}$ & Observed & Expected $^{*}$ \\
\hline \multirow[t]{3}{*}{142} & II (0.915) & 54 & 51 & 10 & 8 \\
\hline & IM (0.085) & 0 & 3 & 0 & 2 \\
\hline & MM (0.000) & 0 & 0 & 0 & 0 \\
\hline \multirow[t]{3}{*}{143} & $\mathrm{HH}(0.997)$ & 53 & 54 & 10 & 10 \\
\hline & $\mathrm{HR}(0.000)$ & 0 & 0 & 0 & 0 \\
\hline & $\operatorname{RR}(0.003)$ & 1 & 0 & 0 & 0 \\
\hline \multirow[t]{3}{*}{146} & NN (0.876) & 54 & 49 & 10 & 8 \\
\hline & NS (0.105) & 0 & 5 & 0 & 2 \\
\hline & SS (0.019) & 0 & 1 & 0 & 0 \\
\hline \multirow[t]{3}{*}{211} & $\operatorname{RR}(0.615)$ & 52 & 30 & 10 & 8 \\
\hline & RQ (0.333) & 2 & 20 & 0 & 2 \\
\hline & QQ (0.051) & 0 & 4 & 0 & 0 \\
\hline \multirow[t]{3}{*}{222} & QQ (0.969) & 54 & 52 & 10 & 10 \\
\hline & QK (0.021) & 0 & 2 & 0 & 0 \\
\hline & KK (0.010) & 0 & 1 & 0 & 0 \\
\hline \multirow[t]{3}{*}{240} & PP (0.295) & 16 & 12 & 3 & 5 \\
\hline & PS (0.465) & 30 & 28 & 7 & 3 \\
\hline & SS (0.239) & 8 & 15 & 0 & 2 \\
\hline
\end{tabular}

${ }^{\text {\#} A l l e l e ~ f r e q u e n c i e s ~ f o r ~ t h e ~ e x p e c t e d ~ n u m b e r s ~ w e r e ~ c a l c u l a t e d ~ u s i n g ~ t h e ~}$ frequencies of the pre-exposed herd

\section{PRNP variants associated with scrapie susceptibility}

When we compared the genotypes of affected and unaffected animals, we found two genotypes to be associated with scrapie susceptibility and two to be associated with resistance. Specifically, we compared the estimated allele and genotype frequencies of the herd prior to exposure with those of affected animals. Of the six variable positions, two (146 and 211) had genotype frequencies significantly different in the affected samples than those expected from the pre-exposed frequencies. There was weak significance for position 146 and similar results have

Table 4 Comparison of the genotypes at position 211 to assess the relative scrapie risk

\begin{tabular}{lllll}
\hline $\begin{array}{l}\text { Genotype } \\
\text { herd }^{\ddagger}\end{array}$ & $\begin{array}{l}\text { Pre-exposed } \\
\text { positive }\end{array}$ & $\begin{array}{l}\text { Scrapie } \\
\text { Rerapie }_{\text {negative }}^{\ddagger}\end{array}$ & $\begin{array}{l}\text { Relative } \\
\text { risk }\end{array}$ \\
\hline RQ & 182 & 64 & 118 & 22 \\
QQ & 125 & 2 & 123 & 1 \\
\hline
\end{tabular}

${ }^{\ddagger}$ Total number of animals in each group, were calculated using the frequencies of the pre-exposed herd been found in other studies, where the homozygous $\mathrm{NN}_{146}$ genotype has been associated with scrapie susceptibility in Cypriot goats $[16,24]$. The homozygous $R_{211}$ genotype was strongly associated with scrapie susceptibility, with the heterozygous $R_{211}$ genotype conferring a degree of protection to the disease.

\section{Effect of position 211 on scrapie susceptibility and resistance}

All the affected animals from herd 1 had at least one allele with arginine (R) at position 211. Specifically, of the 54 affected samples tested, 52 were $R_{211}$, whereas, the remaining 2 were $R Q_{211}$. In the unaffected group, $R_{211}$ was seen in 25 of the 56 samples and $\mathrm{RQ}_{211}$ and $\mathrm{QQ}_{211}$ were seen in 26 and 5 animals, respectively. A similar result was seen in the second herd where all the affected samples were $R_{211}$. These findings indicate that glutamine $(\mathrm{Q})$ at position 211 confers protection to scrapie. The frequency of $\mathrm{Q}$ is usually low and therefore the homozygous $\mathrm{QQ}_{211}$ is seen in very low frequency in most herds, however it has not been seen any of the affected animals reported in the literature (Table 5).

Significant differences between the frequencies of the $R_{211}$ in the unaffected samples compared to the affected samples shows heterozygous goats have a significantly lower susceptibility to scrapie than $R_{211}$ individuals. A comparison of the estimated genotypes of the herd prior to scrapie exposure to the affected animals shows $35 \%$ of the homozygous $R_{211}$ individuals developed the disease, whereas only $1.6 \%$ of the heterozygous $R_{211}$ individuals succumbed. Similar patterns have been reported in the literature. In French goat populations, the risk of succumbing to scrapie for $R_{211}$ and $R_{211}$ to be $30-39 \%$ and $4.4-$ $14 \%$, respectively $[19,21]$. These results highlight the protection provided by the glutamine $(\mathrm{Q})$ at position 211 and low prevalence of the disease in the heterozygous animals.

Although additional studies are required, it is interesting to compare the 211 variant position in goats to position 171, of the $A_{136} R_{154} Q_{171}$ allele in sheep. In sheep, homozygous ARR is considered resistant and homozygous ARQ is susceptible; whereas ARR/ARQ heterozygous sheep are relatively resistant to scrapie [7, 31]. Similar results were found in this study where homozygous $\mathrm{QQ}_{211}$ and $\mathrm{RR}_{211}$ were found resistant and highly susceptible respectively, while there was a very low prevalence of scrapie in $\mathrm{RQ}_{211}$ heterozygous animals. $\mathrm{Al}$ though, scrapie has not been seen in Canadian ARR/ ARQ sheep to date, it has been detected in Europe sheep [31-33]. Statistical models have estimated that genotypes with ARR haplotypes were $1000 \times$ more resistant to the disease compared to homozygous ARQ [33, 34]. In 
Table 5 Comparison of genotypes affected with scrapie from the literature. A total of 544 scrapie cases from various breeds were assessed

\begin{tabular}{|c|c|c|c|c|c|c|c|c|c|c|c|c|c|}
\hline \multirow{2}{*}{$\begin{array}{l}\text { Number } \\
\text { of } \\
\text { affected }\end{array}$} & \multicolumn{3}{|l|}{142} & \multicolumn{3}{|l|}{146} & \multicolumn{3}{|l|}{211} & \multicolumn{3}{|l|}{222} & \multirow[t]{2}{*}{ References } \\
\hline & $\|$ & $\mathrm{IM}$ & $\mathrm{MM}$ & $\mathrm{NN}$ & NS & SS & $\mathrm{RR}$ & $\mathrm{RQ}$ & $\mathrm{QQ}$ & $\mathrm{QQ}$ & QK & KK & \\
\hline 30 & 83 & 1 & 0 & - & - & - & 83 & 7 & 0 & 87 & 3 & 0 & Barillet et al. 2009 \\
\hline 259 & 238 & 21 & 0 & - & - & - & 246 & 13 & 0 & 256 & 3 & 0 & Corbiere et al. 2013 \\
\hline 39 & - & - & - & - & - & - & - & - & - & 39 & 0 & 0 & Vaccari et al. 2006 \\
\hline 27 & - & - & - & - & - & - & 27 & 0 & 0 & 27 & 0 & 0 & Bouzalas et al. 2010 \\
\hline 25 & - & - & - & - & - & - & - & - & - & 25 & 0 & 0 & Acutis et al. 2006 \\
\hline 104 & 103 & 1 & 0 & 104 & 0 & 0 & 104 & 0 & 0 & 99 & 5 & 0 & Fragkiadaki et al. 2011 \\
\hline Total:544 & 424 & 23 & 0 & 104 & 0 & 0 & 460 & 20 & 0 & 533 & 11 & 0 & - \\
\hline
\end{tabular}

this study we estimated $\mathrm{RQ}_{211}$ were $22 \times$ more resistant than homozygous $R_{211}$, suggesting that $R Q_{171}$ in sheep has a stronger influence on resistance than $R_{211}$ in goats. Similar to homozygous ARR sheep, the $\mathrm{QQ}_{211}$ genotype in goats is seen in relatively low frequency [31-33].

Although the mechanism for the conversion of $\operatorname{PrP}^{C}$ to the pathogenic form $\left(\mathrm{PrP}^{\mathrm{Sc}}\right)$ and its pathological effects are poorly understood, specific mutations in sheep PRNP associated with resistance are shown to destabilize the $\operatorname{PrP}^{\mathrm{C}}$ protein [35]. Direct correlation of scrapie susceptibility and mutation induced changes are unlikely as the structural consequence of scrapie associated variants are local. As such, variations in scrapie susceptibility are likely caused by altering protein stability. Destabilizing the structure of $\operatorname{PrP}^{C}$ may increase protease sensitivity and slow amyloidogenesis, thereby preventing $\operatorname{PrP}^{C}$ from being converted to the pathogenic form. This is thought to account for the change from scrapie susceptibility to resistance following a single amino acid substitution $\left(A R Q_{171}\right.$ to $\left.A R R_{171}\right)$ in sheep [36], and perhaps also the inhibition of cell-free conversion following the substitution of $\mathrm{R}$ to $\mathrm{Q}$ at codon 211 in recombinant goat PrP [37].

\section{Position 211 and developing scrapie resistant dairy goat herds in Ontario}

An association of other variants $\left(M_{142}, S_{146}\right.$ and $\mathrm{K}_{222}$ ) with protection towards scrapie was not tested in this study due to low allele frequencies of the potentially resistant allele. $\mathrm{QQ}_{211}$ provided protection regardless of the amino acids at the other positions such as 222. There is a suggestion from challenge studies that $K_{222}$ may confer more resistance than $\mathrm{Q}_{211}$ [22]. In preliminary studies on Ontario dairy goat herds, the frequency of $K_{222}$ has been found to be very low or absent, making elimination of $Q_{222}$ very difficult. The extent to which elimination of $R_{211}$ could result in scrapie resistant herds is of great interest and additional studies on surveying genotype frequencies in Ontario dairy herds are underway.

\section{Conclusions}

The data presented, highlights the association of arginine (R) at position 211 with susceptibility to scrapie and the protective effect of $Q$, irrespective of the amino acids at the other positions. To date there are no programs in place in Canada to select for resistance towards scrapie in goats. A major barrier may be the low frequency of scrapie resistant animals in Canadian goat herds. As the male to female ratio in breeding programs is often 1:20, the genotype of the bucks has a strong impact on the determination of the overall genetic profile of the herd. The most efficient strategy to select against high risk animals, at the same time minimizing the loss of production traits, would be to only utilize more resistant bucks or semen. This would be a particularly useful approach for goat producers associated with a farm previously infected with scrapie, and goat producers providing large numbers of breeding ewes to other producers.

In sheep, breeding for scrapie resistant with ARR/ARR rams has been a successful strategy for the prevention of scrapie outbreaks [38]. Furthermore, increased frequencies of the resistance associated ARR allele, as a result of selective breeding, is assumed to have a population effect by reducing the scrapie infection risk even for animals of susceptible genotypes $[8,39]$. As the protection provided by $R_{171}$ in heterozygous sheep seems to be several folds higher than the protection provided by $\mathrm{Q}_{211}$ in heterozygous goats, selection for homozygous $\mathrm{QQ}_{211}$ goats should be favoured. Breeding for resistance in goats by recruiting bucks with scrapie-resistant genetics, should increase the frequency of resistant alleles in the herd, with a resultant reduction in classical scrapie susceptibility. 


\section{Competing interests}

The author(s) declare that they have no competing interests.

\section{Authors' contribution}

VS carried out the laboratory work, conducted the analyses and drafted the manuscript. GBM provided the samples for this study and helped draft the manuscript. BNW played a critical role in project development, manuscript preparation and obtained the funding to carry out this research. All the authors edited and approved the manuscript prior to submission

\section{Acknowledgments}

The authors acknowledge the support staff in the Transmissible Spongiform Encephalopathy Unit at the CFIA Ottawa Laboratory Fallowfield for outstanding technical assistance, and the CFIA Operations staff involved in sample collection. We thank members of the Natural Resources DNA Profiling and Forensic Center, in particular Nguyen Thi Xuan Nguyen, for assistance with the scrapie genotyping.

\section{Author details}

${ }^{1}$ Natural Resources DNA Profiling and Forensics Centre, DNA Building, Trent University, 2140 East Bank Drive, Peterborough, ON, Canada. ${ }^{2}$ National and OIE Reference Laboratory for Scrapie and CWD, Ottawa Laboratory Fallowfield, Canadian Food Inspection Agency, 3851 Fallowfield Road, Ottawa, ON, Canada. ${ }^{3}$ Livestock Gentec, Department of Agricultural, Food and Nutritional Science, University of Alberta, Edmonton, AB T6G2P5, Canada.

Received: 30 September 2015 Accepted: 15 March 2016 Published online: 22 March 2016

\section{References}

1. Prusiner S. Prions. Proc Natl Acad Sci U S A. 1998:95:13363-83.

2. Andreoletti O, Berthon P, Marc D, Sarradin P, Grosclaude J, van Keulen L, Schelcher F, Elsen JM, Lantier F. Early accumulation of PrPSc in gutassociated lymphoid and nervous tissues of susceptible sheep from a Romanov flock with natural scrapie. J Gen Virol. 2000;81:3115-26.

3. Gonzalez L, Martin S, Siso S, Konold T, Ortiz-Pelaez A, Phelan L, Goldmann W. Stewart P. Saunders G. et al. High prevalence of scrapie in a dairy goat herd: tissue distribution of disease-associated PrP and effect of PRNP genotype and age. Vet Res. 2009;40:65.

4. Goldmann W. PrP genetics in ruminant transmissible spongiform encephalopathies. Vet Res. 2008:39:30.

5. Goldmann W, Hunter N, Foster JD, Salbaum JM, Beyreuther K, Hope J. Two alleles of a neural protein gene linked to scrapie in sheep. Proc Natl Acad Sci U S A. 1990;87(7):2476-80.

6. Baylis M, Goldmann W. The genetics of scrapie in sheep and goats. Curr Mol Med. 2004:4:385-96.

7. Harrington NP, O'Rourke Kl, Feng Y, Rendulich J, DiFruscio C, Balachandran A. Prion genotypes of scrapie-infected canadian sheep 1998-2008. Canadian Journal of Veterinary Research-Revue Canadienne De Recherche Veterinaire. 2010;74:228-32.

8. European Food Safety Authority. Scientific Opinion on the scrapie situation in the EU after 10 years of monitoring and control in sheep and goats. EFSA Panel on Biological Hazards. EFSA Journal. 2014;12(7):3781.

9. Vaccari $G$, Panagiotidis $\mathrm{CH}$, Acin C, Peletto S, Barillet F, Acutis P, Bossers A, Langeveld J, van Keulen L. et al. State-of-the-art review of goat TSE in the european union, with special emphasis on PRNP genetics and epidemiology. Vet Res. 2009;40:48.

10. Billinis C, Panagiotidis C, Psychas V, Argyroudis S, Nicolaou A, Leontides S, Papadopoulos O, Sklaviadis T. Prion protein gene polymorphisms in natural goat scrapie. J Gen Virol. 2002;83:713-21.

11. Acutis P, Bossers A, Priem J, Riina M, Peletto S, Mazza M, Casalone C, Forloni $G, R u$ G, Caramelli M, et al. Identification of prion protein gene polymorphisms in goats from italian scrapie outbreaks. J Gen Virol. 2006;87: 1029-33.

12. Papasavva-Stylianou $P$, Kleanthous $M$, Toumazos $P$, Mavrikiou $P$, Loucaides P. Novel polymorphisms at codons 146 and 151 in the prion protein gene of cyprus goats, and their association with natural scrapie. Vet J. 2007:173:459-62.

13. White S, Herrmann-Hoesing L, O'Rourke K, Waldron D, Rowe J, Alverson J. Prion gene (PRNP) haplotype variation in united states goat breeds (open access publication). Genet Sel Evol. 2008;40:553-61.
14. Vaccari G, Di Bari M, Morelli L, Nonno R, Chiappini B, Antonucci G, Marcon S, Esposito E, Fazzi P. et al. Identification of an allelic variant of the goat PrP gene associated with resistance to scrapie. J Gen Virol. 2006;87:1395-402.

15. Serrano C, Hammouchi M, Benomar A, Lyahyai J, Ranera B, Acin C, el Hamidi M, Monzon M, Badiola J. J. et al. PRNP haplotype distribution in moroccan goats. Anim Genet. 2009:40:565-8.

16. Papasavva-Stylianou P, Windl O, Saunders G, Mavrikiou P, Toumazos P, Kakoyiannis C. PrP gene polymorphisms in cyprus goats and their association with resistance or susceptibility to natural scrapie. Vet J. 2011; 187:245-50

17. Hussain A, Babar ME, Imran M, Haq IU, Javed MM. Detection of four novel polymorphisms in PrP gene of pakistani sheep (damani and hashtnagri) and goats (kamori and local hairy) breeds. Virol J. 2011;8:246.

18. Goldmann W, Ryan K, Stewart P, Parnham D, Xicohtencatl R, Fernandez N, Saunders G, Windl O, Gonzalez L, Bossers A, Foster J, et al. Caprine prion gene polymorphisms are associated with decreased incidence of classical scrapie in goat herds in the united kingdom. Vet Res. 2011:42:110.

19. Barillet F, Mariat D, Amigues Y, Faugeras R, Caillat H, Moazami-Goudarzi K, Rupp R, Babilliot J. M, Lacroux C, et al. Identification of seven haplotypes of the caprine PrP gene at codons 127, 142, 154, 211, 222 and 240 in french alpine and saanen breeds and their association with classical scrapie. J Gen Virol. 2009;90:769-76.

20. Acin C, Martin-Burriel I, Monleon E, Lyahyai J, Luis Pitarch J, Serrano C, Monzon M, Zaragoza P, Jose Badiola J, et al. Prion protein gene variability in Spanish goats. Inference through susceptibility to classical scrapie strains and pathogenic distribution of peripheral PrPsc. Plos One. 2013;8, e61118.

21. Corbiere F, Perrin-Chauvineau C, Lacroux C, Costes P, Thomas M, Bremaud I, Martin S, Lugan S, Chartier C. et al. PrP-associated resistance to scrapie in five highly infected goat herds. J Gen Virol. 2013;94:241-5.

22. Lacroux C, Perrin-Chauvineau C, Corbiere F, Aron N, Aguilar-Calvo P, Maria Torres J, Costes P, Bremaud I, Lugan S. et al. Genetic resistance to scrapie infection in experimentally challenged goats. J Virol. 2014:88:2406-13.

23. Kanata E, Humphreys-Panagiotidis C, Giadinis ND, Papaioannou N, Arsenakis M, Sklaviadis T. Perspectives of a scrapie resistance breeding scheme targeting Q211, S146 and K222 caprine PRNP alleles in greek goats. Vet Res. 2014;45:43.

24. Ortiz-Pelaez A, Georgiadou S, Simmons MM, Windl O, Dawson M, Arnold ME, M. E, Neocleous P, Papasavva-Stylianou P, et al. Allelic variants at codon 146 in the PRNP gene show significant differences in the risk for natural scrapie in cypriot goats. Prion. 2014;8:65-6.

25. Aguilar-Calvo P, Andreoletti O, Fast C, Espinosa J, Lacroux C, Groschup MH, $\mathrm{H}$, Maria Torres J, et al. Influence of prnp variants on the susceptibility of goats to scrapie and BSE. Prion. 2014;8:15-6.

26. Goldmann W, Martin T, Foster J, Hughes S, Smith G, Hughes K, Dawson M, Hunter N, et al. Novel polymorphisms in the caprine PrP gene: a codon 142 mutation associated with scrapie incubation period. J Gen Virol. 1996;77:2885-91.

27. Mitchell GB, O'Rourke Kl, Harrington NP, Soutyrine A, Simmons MM, Dudas S, Zhuang D, Laude $\mathrm{H}$, Balachandran A, et al. Identification of atypical scrapie in Canadian sheep. J Vet Diagn Invest. 2010;22:408-11.

28. Tamura K, Dudley J, Nei M, Kumar S. MEGA4: molecular evolutionary genetics analysis (MEGA) software version 4.0. Mol Biol Evol. 2007;24:1596-9.

29. Bouzalas IG, Dovas Cl, Banos G, Papanastasopoulou M, Kritas S, Oevermann A, Papakostaki D, Evangelia C, Papadopoulos O, Seuberlich T, Koptopoulos G, et al. Caprine PRNP polymorphisms at codons 171 211, 222 and 240 in a Greek herd and their association with classical scrapie. J Gen Virol. 2010;91:1629-34.

30. Fragkiadaki EG, Vaccari G, Ekateriniadou LV, Agrimi U, Giadinis ND, Chiappini B, Esposito E, Conte M, Nonno R, et al. PRNP genetic variability and molecular typing of natural goat scrapie isolates in a high number of infected flocks. Vet Res. 2011:42:104

31. Baylis M, Chihota C, Stevenson E, Goldmann W, Smith A, Sivam K, Tongue S, Gravenor M, et al. Risk of scrapie in British sheep of different prion protein genotype. J Gen Virol. 2004:85:2735-40.

32. Tongue SC, Pfeiffer DU, Warner R, Elliott H, Vilas VD. Estimation of the relative risk of developing clinical scrapie: the role of prion protein $(\operatorname{PrP})$ genotype and selection bias. Vet Rec. 2006;158:43.

33. Arnold M, Ortiz-Pelaez A. The evolution of the prevalence of classical scrapie in sheep in great Britain using surveillance data between 2005 and 2012. Prev Vet Med. 2014;117:242-50.

34. Dubois MA, Sabatier P, Durand B, Calavas D, Ducrot C, Chalvet-Monfray K. Multiplicative genetic effects in scrapie disease susceptibility. C R Biol. 2002;325:565-70. 
35. Rezaei H, Choiset Y, Eghiaian F, Treguer E, Mentre P, Debey P, Grosclaude J, Haertle $T$, et al. Amyloidogenic unfolding intermediates differentiate sheep prion protein variants. J Mol Biol. 2002;322:799-814.

36. Eghiaian F, Grosclaude J, Lesceu S, Debey P, Doublet B, Treguer E, Rezaei H, Knossow $\mathrm{M}$, et al. Insight into the PrPC-> PrPSC conversion from the structures of antibody-bound ovine prion scrapie-susceptibility variants. Proc Natl Acad Sci U S A. 2004;101:10254-9.

37. Eiden M, Soto EO, Mettenleiter TC, Groschup MH. Effects of polymorphisms in ovine and caprine prion protein alleles on cell-free conversion. Vet Res. 2011;42:30.

38. Nodelijk G, van Roermund HJW, van Keulen LJM, Engel B, Vellema P, Hagenaars TJ. Breeding with resistant rams leads to rapid control of classical scrapie in affected sheep flocks. Vet Res. 2011;42:5.

39. Hagenaars TJ, Melchior MB, Bossers A, Davidse A, Engel B, van Zijderveld FG. Scrapie prevalence in sheep of susceptible genotype is declining in a population subject to breeding for resistance. BMC Vet Res. 2010;6:25.

Submit your next manuscript to BioMed Central and we will help you at every step:

- We accept pre-submission inquiries

- Our selector tool helps you to find the most relevant journal

- We provide round the clock customer support

- Convenient online submission

- Thorough peer review

- Inclusion in PubMed and all major indexing services

- Maximum visibility for your research

Submit your manuscript at www.biomedcentral.com/submit
Biomed Central 